\title{
Aprovechamiento de recursos forestales en la Edad Media: una apuesta interdisciplinar para su estudio en zonas de media montaña mediterránea
}

\author{
Use of forest resources in the Middle Ages: an interdisciplinary \\ approach to the study in Mediterranean mid-mountain areas
}

Marta SANCHO PlanAS

\begin{abstract}
Author:
Marta Sancho Planas

Profesora de Historia y Arqueología de la Universitat de Barcelona. Secretaria del Institut de Recerca en Cultures Medieval. Universidad de Barcelona (Barcelona, Spain)

msancho@ub.edu

https://orcid.org/0000-0002-6916-5220

Date of reception: 16/03/21

Date of acceptance: 10/05/21

\section{Citation:}

Sancho Planas, M. (2021). Aprovechamiento de recursos forestales en la Edad Media: una apuesta interdisciplinar para su estudio en zonas de media montaña mediterránea. Anales de la Universidad de Alicante. Historia Medieval, (22), 191-217. https://doi.org/10.14198/medieval.19392

\section{() 2021 Marta Sancho Planas}

Licence: This work is licensed under a Creative Commons Attribution 4.0 International License (CC BY 4.0).
\end{abstract}

\section{RESUMEN}

El objetivo de este artículo es destacar la importancia de la explotación de los recursos forestales en época medieval, a menudo ignorada y muy poco tratada en los textos especializados en este período. El principal obstáculo para el estudio de este tipo de actividades reside en la escasez de fuentes y la poca concreción de estas. Por ello se hace necesaria la utilización de fuentes muy diversas. La metodología empleada parte de la selección y análisis de documentación medieval con el fin de encontrar indicios de estas actividades (topónimos, productos...), posteriormente se ha recopilado información procedente de la arqueología, la iconografía y la etnología y se han establecido comparaciones de los datos obtenidos. Por lo que respecta al ámbito geográfico nos centramos en la zona correspondiente a la Cataluña actual. Se trata de un territorio caracterizado por un relieve accidentado en el que las tierras llanas son muy escasas. El clima mediterráneo que le es característico se ve alterado por la presencia de los Pirineos y la extensa línea de costa favorece los contactos a través del mar. Cronológicamente procuramos focalizar muestro estudio en la alta edad media, aunque no siempre nos ha sido posible encontrar datos correspondientes a dicho período por lo que 
a menudo debemos recurrir a fuentes de cronología posterior. El resultado final es la identificación de una gran variedad de actividades productivas, de recolección y semiagrícolas, que aprovechan los recursos forestales y que muestran un cierto equilibrio con otras actividades como la agricultura y la ganadería.

PALABRAS CLAVE: explotación del bosque; territorio medieval; recolección; semiagricultura; economía rural.

\section{ABSTRACT}

The aim of this paper is to highlight the importance of forest exploitation in medieval times. The main obstacle to the study of these activities lies in the limited sources and poor concretion of them. To the silence of the written texts, we must add the few concrete data from archaeological activity. However, medieval iconography shows a variety of objects and products made from forest resources, many of them present, too, in the traditional world. The methodology includes the analysis of documents, cartographic and toponymic work archaeological data and finally the comparison with data from ethnology and iconography. From a geographical point of view, we focus on the area corresponding to present-day Catalonia. It is a territory characterised by a rugged relief in which flat lands are very scarce. The characteristic Mediterranean climate is altered by the presence of the Pyrenees and the extensive coastline favours the contacts across the sea. Chronologically, we have tried to focus our study on the High Middle Ages, although it has not always been possible to find data corresponding to this period, so we often must resort to sources of later chronology. The result is the identification of a variety of productive activities, gathering and semi-agriculture, that exploit the forest resources and show a certain balance with other activities such as farming and ranching.

KEYWORDS: forest exploitation; medieval territory; gathering; semi-agriculture; rural economy.

\section{INTRODUCCIÓN: ESTADO DE LA CUESTIÓN}

La Edad Media resulta para muchos, un período oscuro y poco atractivo por lo que respecta a la explotación de recursos y a las técnicas productivas. La visión que se nos muestra de la economía rural de época medieval suele estar dominada por las tareas agrícolas centradas principalmente en el cultivo de cereales de secano, complementados por la vid y el olivo, algunos árboles frutales y las huertas. La ganadería, considerada siempre como una actividad secundaria, es citada en los textos de forma tangencial y nada o casi nada se suele decir de la explotación del bosque. A pesar de esta situación, algunos autores han realizado estudios de gran interés sobre la explotación de los recursos forestales -Amouric (1990); Bonhote et al. (1988); 
Higounet (1966); Wickham (1990)- aunque son muchos más los que destacan la importancia de estos recursos, sin que las fuentes que utilizan les permitan profundizar y detallar cuales fueron y de qué forma se explotaron -Clemente (2001); Guilaine (1991); Pinna (1990)-. Dichos autores merecen un gran reconocimiento pues gracias a sus aportaciones se ha puesto sobre la mesa dicha temática y han alertado de su importancia.

Esta situación es debida a la base documental sobre la que se han fundamentado la mayor parte de los estudios sobre economía rural en época medieval. Los textos escritos conservados en los archivos para los siglos altomedievales, poco o nada nos dicen de estas actividades. La razón debemos buscarla en la misma naturaleza de estos documentos en los que, principalmente se trata de transacciones de bienes inmuebles (donaciones, compra-ventas, testamentos...) de propiedad privada, laica o eclesiástica, pero difícilmente se hace referencia a aquellos recursos de tipo comunal, sobre los que los habitantes de un determinado lugar tienen derechos de uso, y este es el caso de buena parte de los recursos forestales.

A pesar del poco interés de la historiografía en investigar sobre un tema de por sí raramente representado en los textos escritos, contamos con aportaciones muy valiosas. Algunos autores se han esforzado en extraer, de los textos escritos, datos acerca de la explotación del medio natural por parte de las comunidades medievales. $\mathrm{Al}$ respecto debemos indicar el volumen que recoge las ponencias y comunicaciones presentadas en el ler Congreso sobre ecohistoria e historia medieval (Clemente, 2001). Su lectura refleja la escasa especialización que presenta esta tendencia historiográfica en nuestro país y la necesidad de avanzar a partir de nuevos enfoques metodológicos capaces de aportar visiones inéditas de las interacciones entre la sociedad medieval y su entorno.

En este sentido, resulta interesante el enfoque que nos ofrece la magnífica obra de M. Lombard (1978) en la que aborda el tema de las fibras usadas en la producción textil en el ámbito musulmán entre los siglos VIII y XII. El autor utiliza fuentes clásicas y árabes y construye un discurso altamente interesante en el que plantea la relación entre las fibras de uso habitual desde la Antigüedad -el lino y la lana- y las innovaciones que se producen en los siglos medievales con la introducción de nuevos materiales como el algodón y la seda. De este trabajo y en relación con el estudio que planteamos, nos resultan útiles las referencias al lino, fibra que también encontramos en el entorno cristiano desde los siglos altomedievales. A pesar de su interés, esta obra se aleja mucho de nuestros objetivos, centrados principalmente en las prácticas recolectoras y semiagrícolas que nuestros antepasados medievales pudieron llevar a cabo para abastecerse de productos vegetales diversos con aplicaciones muy variadas.

En el año 1990 se celebró un encuentro dentro de la Settimane di Studi del Centro Italiano di Studi sull'Alto Medioevo, Spoleto que versaba sobre Lambiente vegetale 
nell'alto medioevo. A pesar de que la mayoría de las aportaciones se centraban en aspectos agrícolas y ganaderos desde las fuentes escritas, algunos autores presentaron temáticas relacionadas con los recursos forestales entre ellos, Ch. Wickham (1990); sobre el clima, como M. Pinna (1990) o a partir de fuentes arqueológicas, en el caso de R. Nöel (1990).

La arqueología, dentro a la innovadora línea de investigación sobre la evolución del paisaje, nos aporta una metodología y muy especialmente, una teoría que nos permite adentrarnos en el análisis de las formas de explotación de los recursos de todo tipo, incidiendo en aspectos como la distribución y organización del territorio en relación con la explotación de determinados recursos, las técnicas aplicadas en estas actividades, la percepción del entorno y la optimización de los recursos respondiendo a las necesidades de la comunidad, Bolòs (1982); Camiade et al. (2005); Catafau (2002); Davasse et al. (1990); Rendu (1994); Riera et al. (1994); Sancho (2005). El esfuerzo de comparación de los datos obtenidos con la información procedente de estudios etnológicos (etnoarqueología) e iconográficos, nos permite establecer continuidades y comprender aquellas huellas de las actividades productivas de época medieval que han quedado fosilizadas en el paisaje.

Pero allí donde la arqueología nos aporta mayores resultados, es en la línea de los estudios paleoambientales realizados a partir de los análisis de macro y micro restos tales como carbones, semillas o pólenes entre otros. Sus propuestas parten de análisis multi-proxy, es decir a partir de diversos tipos de indicadores paleoambientales, bióticos y abióticos que posteriormente pueden ser contrastados con datos procedentes de los textos escritos y de la arqueología tradicional. Dichas aproximaciones nos ofrecen una visión de largo recorrido de la evolución del paisaje por lo que respecta a la cobertura vegetal y a los procesos de erosión y sedimentación y nos indican el avance o retroceso de determinadas actividades productivas como la agricultura o la ganadería. Dentro de estos estudios destacamos el realizado por S. Riera, G. Wansard y R. Julià en las inmediaciones del lago de Estanya, en el Prepirineo aragonés. En este estudio se pudo identificar, para los siglos medievales, una intensa actividad productiva relacionada con el aprovechamiento de determinadas especies vegetales propias de entornos lacustres, especialmente el cáñamo (Riera, Wansard, Julià, 2004, pp. 311-319). Los diversos proyectos, liderados por el Institut Català d'Arqueologia Clàssica, sobre la evolución paleoambiental en zonas pirenaicas, ha dado sus frutos y actualmente disponemos de conocimientos sólidos acerca del impacto de la actividad humana en estos territorios desde épocas prehistóricas hasta la actualidad (Palet, et al, 2011). Mención especial merecen los estudios paleoambientales centrados en el análisis de carbones procedentes distintos entornos arqueológicos, entre los que destacan los realizados en relación con la producción de hierro (Izard, 2005, 2009). A través de ellos podemos observar cuales fueron los tipos de madera más utilizados en la producción de carbón. 
Las tareas propias del mundo rural tradicional son una constante fuente de inspiración para todos aquellos que nos dedicamos al estudio de las técnicas productivas de época medieval, y muy especialmente si nuestro interés se centra en las actividades propias del mundo rural y del aprovechamiento de recursos.

El establecimiento de paralelismos entre dichas prácticas y las que se llevaban a cabo en la Edad Media no es una tarea fácil dada la escasez de fuentes escritas medievales que nos acerquen a ellas. A pesar de ello son muchas las evidencias indirectas que nos informan sobre una cultura material diversa con objetos cotidianos similares a los que podemos encontrar, aun en la actualidad, en determinados entornos rurales, a menudo relegados a una función meramente estética.

Desgraciadamente, la sensación constante de pérdida de conocimientos ancestrales se agudiza cada día que pasa y, sin que esta sea una tendencia novedosa, existen un buen número de investigadores del mundo tradicional que se esfuerzan en dejar constancia de aquello que fue y ya no existe.

En el ámbito de trabajo en el que nosotros nos movemos, podemos recordar las aportaciones de etnólogos tan destacados como Ramon Violant i Simorra que ya en 1949 nos advertía de la pérdida de conocimientos en el mismo título de su obra El Pirineo español. Vida, usos, costumbres, creencias y tradiciones de una cultura milenaria que desaparece. En paralelo Júlio Caro Baroja dirigía la Revista de Dialectología y Tradiciones Populares y publicaba un gran número de artículos sobre temas diversos relacionados con la cultura popular y tradicional, algunos de los cuales recopilados en la obra Tecnología Popular Española. Uno y otro insistían en remarcar la relación existente entre la Edad Media y las actividades productivas tradicionales, realidad que continuamos constatando en nuestros estudios e investigaciones.

Ambos autores generaron un volumen considerable de información que posteriores investigadores han utilizado como base para sus estudios, J.L. Mingote (1986), J. Roma (2006), J. Solà (2003), por citar algunos. En Catalunya la institucionalización de la recopilación de datos etnológicos dio lugar al proyecto IPEC (Inventari del Patrimoni Etnologic de Catalunya) que, aunque algo disperso, ha conseguido reunir una ingente cantidad de datos referentes a nuestra cultura tradicional y popular (Català, Costa, Folch, 2008).

En nuestro caso, el conocimiento de la obra de estos y otros autores se funde con la propia experiencia, marcada por una progresiva aproximación al mundo rural, primero desde la experiencia vivida y progresivamente con una mirada más académica, estructurada alrededor de la formación en el campo de la arqueología y del medievalismo.

La fascinación por la efectividad de las sencillas técnicas aplicadas a la producción, las habilidades propias de los actores y la capacidad de adaptación y optimización de recursos presente en toda actividad tradicional, contrasta fuertemente con nuestro entorno inmediato, marcado por la complejidad de nuestros procesos pro- 
ductivos, la escasa habilidad en el manejo de herramientas manuales y el constante despilfarro de energías y materiales que caracteriza nuestra sociedad.

Algunos autores se han fijado en la iconografía para obtener datos relacionados con la cultura material desaparecida del registro arqueológico. Sus aportaciones, aunque modestas, son una llamada de atención sobre las posibilidades de este tipo de fuentes. En esta línea, los trabajos realizados por J.L. Mingote, centrados en la Edad Media nos han servido para valorar estas fuentes en las que podemos observar, por ejemplo, cestos, sombreros y bastones documentados a través de la iconografía altomedieval. (Mingote, 1986, pp. 303-312).

Hace unos pocos años, en las XXXIIIes Journées internationales d'histoire et d'archéologie d'Antibes, se plantearon temas relacionados con las herramientas usadas en el trabajo de materias vegetales. Una de las aportaciones se centró en la Edad Media y verso sobre las herramientas para adquirir y transformar la madera (Burri et al., 2013). Aunque tampoco es este nuestro enfoque, los autores de este estudio abordan el tema utilizando la misma variedad de fuentes que nosotros proponemos, textos, iconografía, arqueología y etnografía.

Al iniciar este trabajo somos conscientes de sus limitaciones y muy probablemente los resultados podrán parecer al lector poco relevantes. Creemos que es el momento de mostrar su interés y valorar en qué punto se encuentra la investigación. Esperamos poder construir una visión más completa de la cultura material de nuestros antepasados medievales.

A pesar de ello consideramos que la atención a estas actividades y a la explotación y utilización de determinados recursos vegetales, nos permite disponer de una visión más completa de la cultura material de nuestros antepasados medievales.

\section{CÓMO PLANTEAMOS NUESTRA INVESTIGACIÓN: OBJETIVOS Y METODOLO- GÍA}

El objetivo que nos planteamos se centra en identificar actividades productivas vinculadas a especies vegetales no cultivadas pero explotadas en la Edad Media y proponer la posibilidad de que, algunas de ellas, fueran cuidadas o potenciadas en el mismo lugar en el que se desarrollan espontáneamente. Este tipo de cuidado, que podemos considerar como semi-agricultura, se encuentra en el origen de las actividades agrícolas propiamente dichas y ha sido objeto de estudio para otros períodos históricos (Fisher, 2007).

El término semi-agricultura es utilizado, en la actualidad, para referirse a aquella actividad agrícola que es desarrollada por personas que dedican parcialmente su tiempo de trabajo a la agricultura, en combinación con tareas industriales o propias del entorno urbano (Inoka et al., 2006; Hongbin, Ning, 2004). Encontramos también este término relacionado con tribus indias americanas parcialmente cazadoras- 
recolectoras y semiagrícolas (Clifton, 1978; Hann, 2003). Adaptamos este término para aplicarlo a la Edad Media, para referirnos a aquellas prácticas productivas que no pueden calificarse de agrícolas al no suponer la creación de campos de cultivo ni tareas agrícolas propiamente dichas. Nos referimos a actuaciones de cuidado de especies vegetales, en su entorno natural, para favorecer su crecimiento y aumentar su producción. Este tipo de prácticas van un poco más allá de la simple recolección y se limitan a acciones puntuales como la poda, el desbroce y clareo con la finalidad de eliminar otras especies competidoras.

En ocasiones, los textos escritos de época medieval nos ofrecen pequeños indicios sobre determinadas actividades. La misma utilización del nombre de algún tipo de árbol o planta en la definición del territorio, como topónimos o como complementos que definen un determinado lugar, nos sugiere el interés que estas variedades pudieron tener para los hombres y mujeres de la Edad Media que habitaron estos lugares.

La arqueología y sus aportaciones a la cultura material nos facilitan datos sobre la presencia de determinados objetos y materiales. En otras ocasiones, es la iconografía la que nos muestra escenas repletas de espacios, objetos y actitudes de las que se desprenden actividades productivas sobre las que escasean las informaciones directas.

Todo este material, de difícil sistematización por ser de naturaleza distinta, constituye un conocimiento a veces disperso, pero de gran valor, capaz de hacernos comprender, identificar e interpretar de una forma más rica las condiciones de vida de nuestros antepasados medievales. El trabajo con fuentes tan dispares en su naturaleza conlleva dificultades añadidas a la investigación. Por nuestra parte intentamos encontrar evidencias en las que, como mínimo, coincidan dos de las fuentes, y utilizamos los datos procedentes de los estudios etnológicos para corroborar o reforzar los datos procedentes de fuentes históricas.

Somos conscientes que nuestra experiencia y conocimientos adquiridos a través de lecturas e investigaciones, está fuertemente mediatizado por las características propias de la zona donde vivimos y trabajamos, por su clima, sus condicionantes geográficos y sus características geológicas, de tal forma que difícilmente podemos extrapolar los resultados a otros lugares. El clima mediterráneo es nuestro entorno y, dentro de él, las zonas de media montaña con un relieve acusado y con alturas que oscilan entre los 300 y los 1800 metros. Espacios y paisajes, algunos de ellos, que estuvieron densamente poblados en los siglos medievales, con una cantidad significativa de asentamientos situados en altura, a medio camino entre los valles y las cumbres.

Como objetivos específicos nos proponemos identificar actividades productivas vinculadas a la explotación de recursos forestales que se desarrollaron en los siglos medievales; aportar datos procedentes de fuentes diversas para cada una de estas actividades; sugerir formas de acercamiento al conocimiento de estas actividades ya sea con datos directos o indirectos y finalmente proponer un encaje de estas activi- 
dades dentro de las economías rurales de la Edad Media y visualizar su importancia dentro de ellas.

Se trata de una ventana abierta en el espacio y en el tiempo, un muestreo de actividades del que pensamos deducir un modelo de explotación de recursos que pueda servir de ejemplo comparativo para otras realidades y al mismo tiempo una propuesta metodología capaz de superar el silencio de las fuentes documentales y la escasez de datos arqueológicos adecuados para estudiar las actividades productivas centradas en el aprovechamiento de la vegetación silvestre.

Por lo que respecta a las fuentes escritas hemos escogido dos volúmenes que reúnen una cantidad importante de documentos de la Alta Edad Media: el Cartulario de Sant Cugat del Vallés (Rius, 1945-1947) y la recopilación documental realizada por Ramon d'Abadal para el Pallars y la Ribagorza en el volumen de la Catalunya Carolíngia (Abadal, 1955). La elección responde a la voluntad de obtener datos procedentes de una zona próxima a la costa, marcadamente agrícola y cercana a centros urbanos, por una parte y de una zona montañosa, cercana a los Pirineos, caracterizada por su actividad ganadera y por la explotación de recursos forestales y minerales, de la otra. Ello nos facilitará establecer comparaciones entre uno y otro entorno. Dada la escasez de referencias relacionadas con especies vegetales silvestres, hemos incorporado algunos documentos procedentes del Liber Feudorum Maior (Miquel, 1945), de monasterios pirenaicos como el de Santa Maria de Gerri (Puig, 1992) y actas de consagración de iglesias procedentes del Arxiu Diocesà d'Urgell (Baraut, 1978). Estos documentos nos eran conocidos con anterioridad a la realización de este estudio y hemos optado por utilizarlos a pesar de que puedan parecer un añadido inconexo con los dos volúmenes antes citados.

En relación con la iconografía utilizada, esta es múltiple y variada. Paro los siglos XI-XII hemos utilizado los calendarios, como los de San Isidoro de León, Santa Maria de Ripoll o el representado en el Tapís de la Creació de Girona, las escenas de trabajo de las distintas versiones del Beato de Liébana y de la Bíblia Sacra y las magníficas imágenes del Tapiz de Bayeux. Aunque pertenecientes a la Baja Edad Media (s. XIV-XV), también hemos recogido imágenes del Codex Granatensis, en el que se recoge la obra de Tomas Cantimpré De natura rerum y el Tacuinum Sanitatis de Ibn Butlán, ambos con imágenes muy detalladas de árboles, plantas y actividades desarrolladas en la naturaleza. Estas obras nos aportan un catálogo de objetos y de acciones, escenas en las que aparecen productos y materias primeras procedentes del mundo vegetal, ya sean fibras, maderas o frutos. Sus miniaturas ilustran unos textos conocidos con anterioridad a las copias conservadas por lo que reflejan una realidad más tardía a los textos en sí. A pesar de la dispersión cronológica y geográfica, creemos que debemos utilizarlas ya que nos aportan una información valiosísima con la que podemos establecer relaciones con otras fuentes disponibles. 
Los datos procedentes de la arqueología son el fruto de las investigaciones realizadas en los últimos años en zonas de montaña y media montaña de Cataluña. Entre ellas destacamos las prospecciones e intervenciones realizadas en el Valle del Madriu, en la Sierra del Cadí y en el Valle de Núria por un equipo del Institut Català d'Arqueologia Clàssica; los trabajos realizados en la Sierra del Montsec por un equipo de la Universitat de Barcelona; las investigaciones llevadas a cabo por un equipo de la Universitat Autònoma de Barcelona en el Parc Nacional d'Aigüestortes i Estany de Sant Maurici y otras intervenciones puntuales en yacimientos de época medieval de menor relevancia (Riera, 1994; Palet et al. 2007; Pelachs, 2005; Ollich, 2003, Gassiot, 2016; Rendu et al.,1994; Sancho, 2018, Izard, 2005 y 2008; Bonhote et al., 2002; Davasse et Galop, 1989; Nieto y Raurich, 1998; Raurich et al., 1994). De estas actuaciones y de las analíticas que contienen, se desprenden datos sobre actividades productivas relacionadas con la explotación del bosque e informaciones paleoambientales de gran interés.

La etnología nos aporta información sobre actividades y objetos del mismo modo que la observación del mundo tradicional. Así, pues, junto a obras de autores ya citados, (Caro Baroja, Violant i Simorra, Mingote Calderon), también utilizamos datos procedentes del proyecto IPEC (Solà, 2003) antes mencionado y obras menores, memorias y recopilaciones locales sobre actividades que ya sólo forman parte de la memoria de algunos pocos (Castells, 1999).

Finalmente debemos indicar que en este artículo no hemos podido incluir la parte dedicada a las aplicaciones y usos medicinales, culinarios y como alimento humano y del ganado de flores, frutos, raíces y hojas. Ello se debe a la gran cantidad de utilidades que hemos documentado en el ámbito tradicional pero que no hemos podido rastrear aun en fuentes medievales.

\section{COMBUSTIBLE, CONSTRUCCIÓN Y GUERRA: TRES APLICACIONES DE MÁXI- MO CONSUMO}

\subsection{La madera como combustible}

El bosque mediterráneo, y las zonas limítrofes no cultivadas, ofrecen una gran variedad de especies vegetales de distintos tipos y calidades. Para la optimización de estos recursos resulta imprescindible disponer de unos buenos conocimientos de sus características, lo que permitirá escoger aquella variedad que mejor se adapte a cada necesidad: madera para la construcción, la carpintería y la fabricación de pequeños utensilios; leña y carbón como principal y único combustible.

En la Edad Media, la utilización de los recursos forestales como combustible, ya sea en forma de madera o de carbón vegetal, es sin duda alguna, la actividad que más volumen de materias de origen vegetal consume. Su uso en el ámbito doméstico 
para la calefacción, la cocción de alimentos y la iluminación, incide directamente en la calidad de vida de las personas. En el ámbito productivo podemos destacar su aplicación en la siderurgia, la producción de cerámica, vidrio, cal y yeso y en todas aquellas actividades en las que fuera necesario el calor para transformar una determinada materia. Una buena gestión de la madera aconseja no utilizar un determinado tipo o calibre de leña si no es necesario. Así pues, no se utilizará carbón más que para la producción siderúrgica ni se empleará leña de gran calibre para producciones que no precisa de procesos largos. Los estudios realizados en plazas carboneras indican que mayoritariamente se utilizaba la encina (Quercus ilex) y el roble (Quercus faginea) para la producción de carbón (Bonhote, 1998; Bonhote et al, 2002; Izard, 2009). Los mismos autores documentan el carbón de haya en zonas pirenaicas, especie no muy representada en el bosque mediterráneo, aunque la presencia de un bosque residual de hayas (Fagus sylvatica) y algunos topónimos significativos, pudiera sugerirnos la presencia de este árbol a principios de la Edad Media, en lugares donde no se encuentran en la actualidad ${ }^{1}$. El carbón vegetal sería el combustible con más capacidad calorífica de todos los utilizados en la Edad Media, mientras que los haces de leña procedentes de la limpieza del sotobosque y de una poda controlada de los árboles, aportarían el combustible suficiente para procesos de producción tales como la cal, el yeso, la cerámica o, dentro del ámbito más doméstico, el pan. En los documentos estudiados encontramos topónimos como el barranc de carboneres o la Fonte carbonella (Sancho, 1999: 191-195) en el que la prospección arqueológica nos ha permitido localizar zonas clareadas de bosque -las plazas carboneras- donde se construían las carboneras².

En la Edad Media, la producción de carbón debemos relacionarla con la industria siderúrgica, debido a la necesidad de esta industria de disponer de un combustible de alto rendimiento calorífico. Esta relación ha podido ser demostrada a través de los estudios basados en análisis antracológicos realizados en diversos valles pirenáicos (Bonhote, et al., 2002, pp. 220-221; Euba, 2009, pp. 26-27; Pelachs, Soriano, 2003, Izard, 2005).

En algunas zonas de alta y media montaña, el carboneo generalizado acompañado del pasto de ganado propició la formación de un paisaje deforestado o de bosque abierto muy característico y que ha pervivido hasta nuestros días. Este proceso de deforestación, que pudo producirse en distintas etapas, tiene, en los primeros siglos medievales (s. VII-IX), un momento álgido que ha sido muy bien detectado a través

1 Baraut, C.: (1983) "Les actes de consagracions d'esglésies", Urgellia VI, doc.752, año 1063: Et ad-Sancti Aziscli de Olzina manda lexare... Miquel Rosell, F: Liber Feudorum Maior, Barcelona,1945, doc. 57, pág. 72, año 1010: ... in ipsas elcinas comitales... Abadal, R. d'. 1926-52. Catalunya Carolingia II. Els diplomes carolingis a Catalunya. IEC, Barcelona., vol.III, doc. 267, año 984: ... ipso collo de Elecina. Este topónimo aparece en diversos documentos y nos limitamos a citar la primera mención.

2 Corral Lafuente, J. L.: (1984) Cartulario de Alaón (Huesca), Zaragoza, doc. 224, pág. 216, año 1010: ...de illa fonte que dicitur Carbonella. 
de los análisis polínicos realizados en distintos valles pirenaicos (Palet et al., 2007, pp. 243-245). La iconografía también nos aporta magníficas imágenes como la del Codex Granatensis en la que se aprecia una escena de carboneo completa ${ }^{3}$. Así mismo, está bien documentado por parte de los estudios etnológicos y por testimonios orales (Castells, 1999, pp. 103-107).

La recolección de madera como combustible para el hogar o para actividades productivas que no precisan el carbón, aparece escasamente en los textos escritos (Bolòs, 2004, pp. 342-343), se deduce por los hogares excavados (Ollich, 2003), se visualiza en la iconografía ${ }^{4}$ y se constata a través de la etnología (Violant i Simorra, 1985, pp. 194-206). En este aspecto cabe destacar la importancia de una correcta gestión del bosque, tarea que en la cultura tradicional recae en el común o asamblea de vecinos (Solà, 2003, pp. 28-29; Bringué, 2003; Beltran, Vaccaro, 2007). Poco más podemos documentar de esta importante actividad que debía ocupar una gran cantidad de horas de trabajo, ya fuera en la tala de determinados árboles, en el troceado, en el transporte y en el almacenamiento. En las encuestas realizadas dentro del proyecto IPEC, uno de los informantes remarcaba la diferencia entre una rama caída de un árbol en medio del bosque, la cual podía ser recogida por cualquiera, de un montón de leña cortada y ordenada, la cual tenía el valor añadido del trabajo realizado y en caso de cogerla se podía considerar un hurto ${ }^{5}$. Otro de los informantes nos sorprendía con un comentario muy significativo ante un magnífico ejemplar de encina de su propiedad. Mientras el encuestador veía un árbol centenario digno de ser protegido, bajo el cual podían desarrollarse actividades lúdicas muy gratificantes, el encuestado contaba las cargas de leña que saldrían de dicha encina, la cual, al poco tiempo, fue cortada y vendida como leña de calidad ${ }^{6}$. Este episodio nos permitió comprender la distinta percepción de los recursos que pueden tener aquellos que van de visita a entornos rurales de aquellos que viven en ellos. Trasladar estas experiencias y realidades a la Edad Media no resulta fácil por falta de datos contrastables, pero tener en cuenta este tipo de prácticas nos puede ayudar a detectar indicios en las fuentes medievales.

A pesar de no disponer de datos concretos para la Edad Media, podemos afirmar que las tareas de recolección de leña, ya fuera para producir carbón o como combustible directo, precisaban de una planificación en la gestión del recurso, una planificación que afectaba a toda la comunidad con derechos de uso y explotación de los bosques, un conocimiento real y profundo de las distintas variedades de árboles, de sus características y potencial a partir del cual la leña era destinada a uno

3 Codex Granatensis, fol89r. http://digibug.ugr.es/handle/10481/6525 [consulta 02/03/2021]

4 Codex Granatensis, transportando leña, fol.90v y cortando leña, fol 91v. http://digibug.ugr.es/handle/10481/6525 [consulta 02/03/2021]. Calendario de San Isidoro de León, calentándose en el hogar, mes de febrero

5 Encuesta a J. Cirera de Alzina realizada por J. Solà en el marco del IPEC (Solà, 2003).

6 Encuesta a Elvira Salse de Alzina realizada por J. Solà en el marco del IPEC (Solà, 2003). 
u otro uso en una clara apuesta por la optimización de recursos. Al menos esto es lo que se desprende de la observación del mundo tradicional, aun en la actualidad.

Aunque de forma indirecta disponemos de datos que nos permiten intuir una gestión comunal de los bosques medievales. A partir del s. XIII la demanda externa de productos como el hierro supuso un incremento de la presión sobre el bosque que fue carboneado para producir combustible para la industria siderúrgica ubicada en el Pirineo. Esto conllevó conflictos entre los usuarios tradicionales y los vinculados a esta industria dado que estos últimos no respetaban el equilibrio del bosque dificultando así su recuperación (Bolòs, 2004, pp. 342-343).

\subsection{La madera en la construcción}

El segundo ámbito donde se utiliza una mayor cantidad de recursos forestales es el de la construcción. En nuestra zona de estudio las estructuras de hábitat eran de piedra ligada con mortero de cal y arena y cubiertas de lajas de piedra que se apoyaban sobre un sistema de envigado que precisaba de abundante madera. Las dimensiones de los edificios se adaptaban a los recursos existentes por lo que la luz de las estancias no superaba los cinco metros, dato constatable tanto a través de las edificaciones populares como en las estructuras encontradas en las intervenciones arqueológicas. A pesar del control de las dimensiones de los edificios, la obtención de un gran número de vigas de entre 4 y 5 metros, supone la tala de árboles mucho más altos, dado que sólo se utiliza la parte baja y central del tronco que es la que presenta el calibre necesario. A la techumbre debemos añadir una serie de complementos tales como puertas, ventanas, escaleras, pasarelas, bancos corridos, etc., muchos de ellos documentados a través de las excavaciones arqueológicas en las que se deduce su existencia por la localización de clavos remachados, bisagras o cerraduras y, en caso de incendio, por la presencia de una capa de carbones extensa situada en los accesos y pasos entre estancias (Ollich, 2003; Sancho, 2009). Las vigas y otros elementos constructivos solían ser, en las zonas de media montaña mediterránea, de encina o roble y, en caso de no disponer de ejemplares adecuados, también se utilizaba el pino silvestre. En alta montaña las variedades más utilizadas era pinos, abetos y hayas. Aún en la actualidad las edificaciones tradicionales de más de cincuenta años presentan envigados realizados con estas variedades de gran resistencia y peso.

Aunque no sean visibles al final de la obra, debemos tener en cuenta la madera empleada en la construcción de andamios y la utilizada para hacer los encofrados o para el armazón de los arcos durante su construcción. Las evidencias de encofrados las podemos observar en los agujeros de construcciones como el castillo de Llordá y las señales de encofrados y armazones de arcos son visibles en numerosos monumentos, tanto de carácter laico como eclesiástico. 
La tala se realizaba generalmente con el hacha. Los troncos se retocaban con azuelas o se cortaban en tablones con sierras de dos manos. La iconografía nos ofrece imágenes de estas tareas como la escena del Codex Granatensis en la que aparecen dos personajes cortando tablones ${ }^{7}$. La etnología recoge esta tarea como puede visionarse en un vídeo reproducido en el Museu de la Vida Rural de l'Espluga de Francolí. Ambas imágenes presentan notables paralelismos. Por los documentos sabemos de la existencia de serradoras hidráulicas a partir del siglo XV en los Pirineos, aunque probablemente debieron existir con anterioridad (Bolòs, 2004: 344). La primera serradora hidráulica que encontramos en la iconografía corresponde a uno de los dibujos de Villard de Honnecourt en el que, a pesar de la extraña perspectiva, se aprecia perfectamente el sistema que permitía su funcionamiento ${ }^{8}$.

En determinadas zonas del Pirineo, donde la asamblea del común aun funciona, los nuevos propietarios y vecinos que se instalan en los pueblos son informados del derecho que tienen de extraer un determinado número de vigas de los bosques cercanos. Una vez más nos topamos con la gestión común del bosque y con las limitaciones y normas que han conseguido mantener una explotación sostenible de los recursos forestales (Bringué, 2003; Beltran, Vaccaro, 2007).

En Cataluña, el desarrollo de la industria naval vinculada a la expansión mediterránea y al desarrollo del comercio a partir del s. XIII, fue otra gran consumidora de madera. El pino, la encina y el roble en sus distintas variedades, así como el haya serán las especies más apreciadas y las atarazanas se proveerán de estas maderas procedentes de los bosques más cercanos cuando estos existían 9 .

Los análisis realizados en las maderas de los derelictos excavados, nos muestran una amplia gama de maderas utilizadas en las distintas partes del buque y en diversas investigaciones aportan datos sobre la procedencia de las maderas utilizadas en su construcción (Nieto et al., 1998; Raurich et al., 1994). La construcción naval, como actividad consumidora de grandes cantidades de madera, supuso un cambio en las formas de explotación sostenible del bosque ya que se trataba de una demanda externa que rompió el equilibrio local mantenido hasta el momento.

La tradición de los Raiers, especialistas en bajar los troncos -convertidos en una balsa articulada- por los ríos pirenaicos, nos ofrece una magnífica evidencia del abastecimiento para la construcción naval de todo tipo de maderas: troncos de abeto rectos y altos para los mástiles, pinos, hayas, robles y encinas, para las distintas partes de los buques.

7 Codex Granatensis, fol93v. http://digibug.ugr.es/handle/10481/6525 [consulta 02/03/2021]

8 Puede verse una imagen de este dibujo en https://www.youtube.com/watch? $=$ =IbfDn8ueuTM, [consulta 02/03/2021]

9 Abadal, R. d'. 1926-52. Catalunya Carolingia II. Els diplomes carolingis a Catalunya. IEC, Barcelona, vol. III, doc. 133, pàg. 352-353, año 923: Et in Pinos Altos, similiter. 


\subsection{La madera en la guerra}

No cabe duda de que la actividad bélica consumía una cantidad significativa de madera. Reconocemos nuestra escasa capacidad para abordar este aspecto. No obstante, no podíamos dejar de citarlo por tratarse de una actividad estratégica y de gran impacto en el uso y consumo de materias primeras entre las que se encuentra la madera. Nos limitaremos a citar algunas de sus aplicaciones con la mera intención de testimoniar su incidencia en el tema que tratamos.

Las empuñaduras de todo tipo de armas requerían maderas resistentes a la vez que flexibles, como en el caso de las lanzas para las que el avellano era una de las más adecuadas. La estructura interna de los escudos, recubiertos con pieles o metales, requerían maderas resistentes.

Para la fabricación de arcos y ballestas debieron utilizarse maderas resistentes a la vez que flexibles, entre las que podemos destacar el tejo, el arce y el freso. El astil de las flechas precisa de maderas muy rectas, flexibles y con pocos nudos, siendo las más apreciadas el cedro, el arce y el abeto.

Las máquinas de guerra como las catapultas, los trabuquetes o los arietes, así como las protecciones de campamentos mediante empalizadas o los elementos salientes de los castillos como los matacanes, requerían grandes cantidades de madera de calidad y muy resistente ${ }^{10}$.

\section{PRODUCCIÓN, ÁMBITO DOMÉSTICO Y OCIO: DIVERSIDAD DE APLICACIO- NES Y USOS}

\subsection{Agricultura, ganadería y transformación de productos alimentarios}

La actividad agrícola precisa de madera para la fabricación de herramientas que no requieren el uso del hierro, como horcas empleadas en el manejo de paja y forraje. Para su fabricación se utiliza el almez (Celtis australis), iniciándose el proceso en el mismo árbol, forzando el crecimiento de las ramas a base de ligaduras (Cavanilles, $1795)^{11}$. Otras herramientas de madera son las palas y rastrillos utilizados en las eras, los mayales para la trilla ${ }^{12}$, los mazos para astillar leña, las escaleras para subir

10 Disponemos de una buena síntesis en Hernádez Cardona, X (2001-2004).

11 Rius, J. (1945-1947). Cartulari de St. Cugat del Vallès. CSIC, Barcelona, docs. 183 y 584, año 986 y 1045: in termino de ipso Lodone y prope ipso ledo. En el mismo cartulario aparece en más de siete ocasiones. Abadal, R. d'. 1926-52. Catalunya Carolíngia II. Els diplomes carolingis a Catalunya. IEC, Barcelona., vol.III, docs. 256 y 316, año 979 y 996: ... ipsa villa de Letone..., ipsa alia terra in Letons.

12 Podemos observar una imagen de trilla con mayales en uno de los capiteles del claustro de Santa Maria de l'Estany, y en la Portalada de Santa Maria de Ripoll, ambos del siglo XII y en el mes de Agosto del calendario de San Isidoro de León también del siglo XII. http://www.arquivoltas.com/12-leon/01-SanIsidoro09.htm [consulta 20/04/2021] 
a los árboles o las varas para cosechar aceitunas $\mathrm{u}$ otros frutos como las almendras ${ }^{13}$. En este último caso son especialmente indicadas las ramas de avellano por ser rectas, flexibles, resistentes y poco pesadas ${ }^{14}$.

En este ámbito remarcamos el uso de la madera para la producción de mangos para todas las herramientas ${ }^{15}$, entre los que destacamos toda la estructura de los arados excepto la reja que siempre era de hierro. En estos casos se precisa de maderas duras y resistentes a los golpes por lo que suele utilizarse la madera de roble o encina. Del mismo modo los yugos que uncían los bueyes debían ser de maderas resistentes a golpes y tensiones.

No podemos olvidar en este apartado la cantidad de madera utilizada en el almacenaje de productos agrícolas, especialmente el vino. Los grandes toneles y las pequeñas botas de madera, cuidadosamente conservadas en bodegas y que, según las aportaciones de la etnología, estaban fabricadas con maderas de castaño y roble, principalmente. Los aros que las sujetaban podían ser de hierro, como en el caso de las ferratas, pero también los había de maderas flexibles como el fresno ${ }^{16}$.

También la madera estaba presente en las maquinas elevadoras de agua como las norias y las aceñas, así como en la adecuación de parcelas de regadío en las que a menudo las canalizaciones menores estaban hechas con troncos ahuecados.

Por lo que respecta la actividad ganadera, la madera juega un papel destacado al tiempo que invisible en los textos y en la arqueología. Una vez más serán la iconografía y la etnología las que nos aporten datos de interés. Así pues, el fresno era utilizado para la elaboración de los collarines de donde pendían los cencerros. Los pesebres donde se alimentaban los rebaños eran de madera del mismo modo que los abrevaderos, construidos con troncos ahuecados. Los animales de carga estaban equipados con una gran variedad de aparejos adaptados a cada tipo de producto que debía ser transportado, la mayoría de ellos fabricados con una base de madera recubierta o no de pieles y telas (Castells, 1999, p. 73) ${ }^{17}$.

13 Codex Granatensis, fol90v i fol92r http://digibug.ugr.es/handle/10481/6525 [consulta 02/03/2021].

14 Rius, J. (1945-1947). Cartulari de St. Cugat del Vallès. CSIC, Barcelona, docs. 9, 173, 314 y 578, año 917 , 986, 996 y 1045: torrente que vocant Fonte de Avellano, rio de ipsas avelanedas, rio qui discurrit de avelanedos.

15 Codex Granatensis, fol92r http://digibug.ugr.es/handle/10481/6525 [consulta 02/03/2021].

16 Rius, J. (1945-1947). Cartulari de St. Cugat del Vallès. CSIC, Barcelona, docs. 173, 486 y 505, año 986, 1023 y 1027: per ipso lomar ad iungenten de Fraxano, ipso lomar adiungente de Frexano, in Frexanet. Abadal, R. d'. 1926-52. Catalunya Carolingia II. Els diplomes carolingis a Catalunya. IEC, Barcelona., vol.III, doc. 61, año 867: in rio de Frexaneto. Este topónimo aparece en diversos documentos y nos limitamos a citar la primera mención.

17 Son múltiples las imágenes iconográficas donde vemos representados animales de carga, de trabajo y de cría en los que aparecen collarines, y aparejos para transportar productos diversos. Como ejemplo podemos citar la obra que Ambrogio Lorenzetti pinto al fresco en Sala dei Nove de Siena (s. XIV), la "Alegoría al buen gobierno" donde podemos ver todo tipo de animales con sus aperos. https://commons.wikimedia.org/wiki/File:Ambrogio_Lorenzetti_-_Effects_of_Good_Government_in_the_ city_-_Google_Art_Project.jpg [consulta 20/04/2021] 
Así mismo, en la transformación de alimentos la madera juega un papel destacado. Los recipientes para el transporte de líquidos y el lugar donde se procedía al primer pisado de la uva -folladores-, a menudo ubicados cerca de las mismas viñas, eran grandes ferratas ${ }^{18}$. La maquinaria de los molinos de harina (ruedas motrices, ejes, cobertores de las muelas, tolvas) y de las prensas de vino y aceite (viga, soportes, tornillo...) eran mayoritáriamente de madera: ruedas y ejes de los molinos, vigas y soportes de las prensas, etc. Las maderas deben ser duras por lo que suele utilizarse el roble o la encina. La iconografía nos ofrece magníficas imágenes de esta maquinaria como las prensas que encontramos en el Beato de Liébana ${ }^{19}$, los magníficos molinos flotantes del Martirio de Santa Úrsula de Colonia o el molino de rueda vertical del Luttrell Psalter ${ }^{20}$.

\subsection{Actividades productivas diversas}

Independientemente del consumo de madera como combustible para los hornos i de forma similar a su utilización en los molinos harineros, la madera está presente en múltiples actividades productivas, especialmente aquellas que utilizan la energía hidráulica y que precisan de maquinaria especializada. En este sentido los motores hidráulicos aplicados a la producción de pieles, telas, papel, y hierro, contaban con ruedas motrices, ejes y engranajes, parecidos a los molinos harineros, todos hechos de madera, del mismo modo que los árboles de levas en aquellos procesos que requerían golpear, triturar o machacar algún material. Aunque muy escasas, también encontramos referencias a serradoras hidráulicas en las que la maquinaria era básicamente de madera ${ }^{21}$.

18 Uno de estos recipientes se puede apreciar en la escena de los porteadores como la del uno de los capiteles de San Martín de Fromistá (Palencia) del s. XII https://romanicodigital.blogspot.com/2017/01/saludoscordiales.html [consulta 20/04/2021]. En las excavaciones realizadas en el Castillo de Mur (Lleida), se identificó un hueco en el suelo de un de los ámbitos excavados que se interpretó como la base donde encajar un follador con una cronología del s. XII (Sancho, 2009: 194-197). También encontramos una magnífica representación de un follador en una miniatura de la primera mitad del siglo XIV en el manuscrito conocido como Bodleian Library (MS. Bodl.264, fol. 133) conservado en la Universidad de Oxford https://digital.bodleian.ox.ac.uk/objects/ae9f6cca-ae5c-4149-8fe4-95e6ecalf73c/surfaces/4f7893dd-f7384lc4-b87b-8e404b346ba7/ [consulta 20/04/2021].

19 En la escena de "La ira de Dios" aparece habitualmente una prensa de viga. Estas imágenes fueron objeto de una magnífica exposición que tuvo lugar en el Museo de la Universidad de Valladolid el año 2013 bajo el título "El lagar de la ira de Dios. La prensa de viga en los Beatos medievales". https://commons. wikimedia.org/wiki/File:B_Facundus_209.jpg [consulta 20/04/2021].

20 Molinos flotantes en un detalle del Martyrdom of St Ursula at Cologne, around 1411. Wallraf-RichartzMuseum, Cologne, Germany https://commons.wikimedia.org/wiki/File:Shipmills,_Martyrdom_of_St_ Ursula_at_Cologne_(detail).jpg [consulta 20/04/2021]. Molino hidráulico de rueda vertical en el Psalm 103 del Luttrell Psalter https://commons.wikimedia.org/wiki/File:Psalm_103;_a_watermill_-_Luttrell_ Psalter_(c.1325-1335),_f.181_-_BL_Add_MS_42130.jpg [consulta 20/04/2021].

21 Ver nota 8. 
Especial mención merece la producción de sal mediante evaporación de agua salada. En este caso, el uso de la madera resulta imprescindible por ser el único material que resiste la corrosión producida por la sal. Por este motivo todos los utensilios que debían entrar en contacto con el agua salada o con la sal ya cristalizada, eran de madera: escaleras, canalizaciones, palas, rastrillos, separadores entre eras salineras, etc. En este entorno no era necesario emplear maderas de gran resistencia dado que la madera quedaba empapada de sal la cual confería una notable solidez y resistencia. Por esta razón, las maderas de árboles de ribera, muy rectas y poco pesadas, como el caso de los álamos podían perfectamente ser utilizadas para estas funciones ${ }^{22}$. Aun en la actualidad podemos ver las canalizaciones de troncos huecos en las salinas de Gerri de la Sal, en el Pirineo leridano.

La producción de todo tipo de resinas, aceites y breas merece una especial atención. Entre ellas destaca la pez, empleada para impermeabilizar botas y pellejos de cuero con los que se transportaba el vino, también era utilizada para marcar animales (Orengo, 2010: 275). El desarrollo de la industria naval, especialmente a partir del siglo XIII impulso la producción de pez, al ser utilizada para impermeabilizar los buques. Desde el siglo IX (860) tenemos noticia de la producción de pez en la zona pirenaica a través de un documento de Carlos el Calvo procedente de la Seu d'Urgell donde se especifica el cobro del diezmo de Andorra del hierro y la pez (pega) que allí se producía ${ }^{23}$. La investigación arqueológica llevada a cabo en el valle del Madriu, en Andorra, puso al descubierto un horno de producción de pez del siglo II-III de nuestra era (Orengo, 2010, pp. 264-276) ${ }^{24}$.

Al lado de esta substancia obtenida a partir de maderas de pinos y abetos, encontramos otras de menor importancia como la trementina o el aceite de enebro. Este último se producía en pequeños hornos realizados con recipientes cerámicos semienterrados y recubiertos de leña o bien aprovechando la misma roca para modelar los huecos y canalillos por los que fluía este aceite esencial (Fabrega, 2006, pp. 89-94). En Aragón, unos grabados en la roca de los que no se conocía su origen, fueron identificados recientemente como hornos de aceite de enebro (Benavente, $2013)^{25}$. No resulta nada fácil adjudicar una cronología a estas marcas halladas en las rocas. A menudo se las había confundido con grabados vinculados a algún tipo

22 Rius, J. (1945-1947). Cartulari de St. Cugat del Vallès. CSIC, Barcelona, doc. 564, año 1043: Albareda. Acta de consagración de la iglesia de Santa María, Sant Pere i Sant Esteve de Mur", Catalunya Romànica. Pallars, vol. XV, pág. 354, año 1069: Apendicio de Alberola. Miquel Rosell, F: Liber Feudorum Maior, Barcelona, 1945, doc. 58, pág. 73: ... in ipsa ripa de ipsa Verneta.

23 D'Abadal, 1926-1952: doc IV. ...de decimis Andorrensis pagi ferri et picis.

24 Encontraremos un interesante estudio etnológico con referencias históricas en Fabrega, 2006. Así mismo, M. Teresa Ferrer nos informa sobre la importancia de la producción de pega durante la Baja Edad Media (Ferrer, 1996, pp. 46-47) y de su valor en los mercados mediterráneos (Ferrer, 2012, p. 163).

25 En este artículo pueden verse fotografías muy precisas de las marcas dejadas en la roca por estos pequeños hornos. 
de ritual. En todo caso la falta de memoria sobre los mismos nos está indicando su antigüedad sin precisión alguna.

Su aplicación principal era para uso medicinal, tanto para personas como para animales, y también pudo ser utilizado como base para perfumar ambientes, mezclado con esencias aromáticas diversas y quemado en perfumadores o incensarios ${ }^{26}$. Aunque sin datos concretos que aportar, el uso de resinas como adhesivos es conocido desde épocas prehistóricas y diversas substancias bituminosas pudieron tener múltiples aplicaciones como por ejemplo como combustible para las antorchas.

La falta casi absoluta de fuentes para la Edad Media que nos aporten datos concretos sobre estas producciones no debería impedirnos suponer que efectivamente se llevaron a cabo. Es este un campo por recorrer dentro de las investigaciones del entorno rural en época medieval. En todo caso alertamos sobre este aspecto con el fin de despertar el interés de los investigadores y con la voluntad de identificar evidencias escritas o materiales que pudieran tener alguna relación con ellas.

$\mathrm{Al}$ aprovechamiento forestal debemos añadir las fibras vegetales tales como el lino o el cáñamo (Linum usitatissimum, Cannabis sativa L.) empleados en la industria textil, la alpargatería, la cordelería y la cestería, al lado de otros materiales que no suelen aparecer en la documentación tales como los juncos (Juncus effusus), la sarga (Salix elaeagnos), la caña (Saccharum ravennae) o el carrizo (Phragmites australis), la enea (Typha angustifolia), el esparto (Stipa tenacísima), entre otros ${ }^{27}$. La iconografía medieval nos muestra un gran número de objetos producidos con estos materiales, ignorados en las fuentes escritas y desaparecidos del registro arqueológico, aunque bien testimoniado por las fuentes orales (Castells, 1999, pp. 99-100). En los calendarios de Ripoll y San Isidoro de León se ven cestos en la escena de la vendimia y J.L. Mingote recoge diversos cestos representados en la iconografía medieval (Mingote, 1986, pp. 303-312). No por ello carecen de importancia en el día a día de los hombres y mujeres medievales. Estas especies no eran cultivadas durante la Edad Media sino que se cuidaban en el mismo lugar donde nacían espontáneamente con el fin de mejorar su productividad (Riera et al., 2004, pp. 317-319).

26 Arsenda de Ager legó en su testamento algunos de estos perfumadores (pumbos) la imagen de los cuales podemos ver en los frescos que decoraban la iglesia de Santa María de Mur.

27 Abadal, R. d'. 1926-52. Catalunya Carolingia II. Els diplomes carolingis a Catalunya. IEC, Barcelona., vol. III, docs. 59, 90, 115 y 271 año, 864, 898, 911 y 987 : ... in locum chujusvocabuum est Junchario, ... de parte occidentis in linare..., Vindo tibi ipso cannamare..., Et ad ipsa Sarga... Rius, J. (1945-1947). Cartulari de St. Cugat del Vallès. CSIC, Barcelona, docs. 45, 52, 197, 432 y 568, año, 956, 957, 987, 1011 y 1044: ... de ipso cannadello.., ... in ipso canneto..., ... aput ipso chanamar..., ... in termino que vocant linares..., ... ad ipsa fonte de Iunchosa... Estos topónimos aparecen en diversos documentos y nos limitamos a citar la primera mención dentro de cada publicación. Miquel Rosell, F: Liber Feudorum Maior, Barcelona,1945, doc. 60, pág. 75: in collo de Sarga. Baraut, C.: (1983) "Les actes de consagracions d'esglésies", Urgellia VI, doc. 752, pág. 120: ... linares et cannamares qui mihi advenit de parentorum. 


\subsection{Mobiliario y menaje}

En el ámbito doméstico la madera es utilizada como material para la fabricación de utensilios diversos. La iconografía de la época es rica en ejemplos que debemos tener en cuenta y más aún cuando la documentación -por el escaso valor de los objetos- y la arqueología -por su nula conservación en el registro arqueológicono nos aportan datos sobre este aspecto. En múltiples escenas de la vida cotidiana observamos objetos hechos de madera tales como cuencos y platos, recipientes diversos, taburetes, mesas, bancos, baúles y cajas, cucharas, morteros, etc ${ }^{28}$. Para el almacenaje de líquidos como el agua y el vino se utilizaban recipientes de madera como los toneles o los cubos de madera que denominamos ferratas - por los aros de hierro que sujetaban las duelas de madera que componían la pieza dándole su forma redondeada- ${ }^{29}$. El registro arqueológico prácticamente no conserva evidencias de estos objetos, aunque a menudo se recuperan placas de hierro ligeramente curvadas con clavos remachados que podrían pertenecer a ferratas como las citadas. La arqueología subacuática nos aporta también algunos objetos de madera de carácter doméstico como peines o cucharas, y los cuchillos de hierro nos aparecen sin mango, aunque algunos conservan los clavos con los que se sujetarían las dos partes de este o la espiga que se encastaría en el mango de madera ${ }^{30}$.

En algunos museos se conservan pequeñas cajitas de madera recubiertas con placas de marfil y profusamente decoradas ${ }^{31}$. La mayoría de ellas son producciones andalusíes y podemos considerarlas objetos de lujo. En diversos yacimientos de nuestro entorno se han encontrado piezas de huesos planos decorados y en algunos casos conservaban la marca de los pequeños clavos de bronce con los que eran sujetadas en un soporte de madera. Probablemente estas piezas de hueso emularían las placas de marfil antes citadas y servirían para recubrir pequeñas cajitas de madera donde guardar objetos delicados o de valor (Sancho, 2009, p. 268).

28 Algunos de estos objetos pueden observarse en imágenes de la Santa Cena o en el banquete del Tapiz de Bayeux http://clioweb.free.fr/peda/tapisserie-bayeux.htm [consulta 02/0372021]. Tambien en Codex Granatensis, fol90v. http://digibug.ugr.es/handle/10481/6525 [consulta 02/03/2021].

29 Los toneles que son cargados en los barcos del Tapiz de Bayeux, corresponden a este tipo de recipientes. Pueden verse en http://clioweb.free.fr/peda/tapisserie-bayeux.htm [consulta 02/03/2021]

30 En la intervención subacuática en el lago de Charavines, se han recuperado cucharas de madera correspondientes al período neolítico. Ver https://www.isere-tourisme.com/patrimoine-culturel/musee-archeologique-du-lac-de-paladru [consulta, 02/03/2021]. En 2009, en el Museo de Arqueología Subacuática de Cartagena se realizó una exposición de peines medievales de madera encontrados en el transcurso de la excavación urbana de la casa del Condestable de Pamplona.

31 Tesoros del Museo Arqueológico, Catálogo, núm. 57371, Arqueta de Abderrahman ben Zeiyan. http://ceres.mcu.es/pages/ResultSearch?Museo=MANT\&txtSimpleSearch=Palencia+\%28m\%29\&simpleSe arch=0\&hipertextSearch=1\&search=advancedSelection\&MuseumsSearch=MANT|\&MuseumsRolSearch= 36\&listaMuseos=[Museo+Arqueol\%EF\%BF\%BDgico+Nacional+\%28Colecci\%EF\%BF\%BDn+Tesoros+del+ MAN\%29] [consulta, 02/03/2021] 
El Boj (Buxus sempervirens) por su cualidad compacta, poco porosa y muy homogénea, resulta ser la especie más indicada para la fabricación de utensilios de cocina, así como el castaño y el roble son las maderas más adecuadas para fabricar recipientes contenedores de líquidos ${ }^{32}$. En el mundo tradicional es bien conocida la utilización de las ramas del brezo (Erica arbórea) para la fabricación de escobas y de sus raíces para fabricar pipas ${ }^{33}$. Según las fuentes orales, recogidas dentro del programa del Inventari del Patrimoni Etnologic de Catalunya (IPEC), la de nogal ${ }^{34}$ (Junglans regia) era la madera más apreciada para la fabricación de muebles y el serbal (Sorbus domestica) para los pilones para cortar o trocear con el hacha ${ }^{35}$.

Aunque la cantidad de madera utilizada para este concepto fuera poca, el impacto en la vida cotidiana era importante, dada la condición de uso diario de los diversos utensilios. Por los restos cerámicos recuperados en los yacimientos arqueológicos, deducimos que la vajilla de madera no fue substituida, y aun parcialmente, por la cerámica hasta finales del siglo XIII, cuando aparecen producciones de lujo con formas de platos y cuencos adecuados para la mesa (Beltran, 2007).

\subsection{Ocio y actividades lúdicas}

Los juegos de mesa, bien conocidos a través de la obra de Alfonso X, requerían de la existencia de un tablero que a menudo encontramos en las excavaciones grabado en una laja de piedra y en los que, muy probablemente, la fichas también eran de ese material. Existían, también, tableros de madera de distintos colores y cabe suponer que en algunos casos las fichas también eran de madera ${ }^{36}$. El alquerque, el ajedrez o la versión medieval del backgammon, junto a sus variantes, son algunos de estos juegos que encontramos reproducidos en numerosas miniaturas medievales, entre las que destacan las del Libro de juegos de Alfonso X el Sabio.

Así mismo, debieron existir otros juegos de calle como los birlos o el juego de la pelota en los que bates, birlos o palos de distinta forma eran confeccionados con maderas diversas. Aunque ya del siglo XVI, resulta interesante el cuadro de Pieter Brueghel en el que se pueden identificar más de 80 juegos de calle, entre ellos la peonza, los birlos, la guerra de molinillos y diversos juegos con palos.

32 Rius, J. (1945-1947). Cartulari de St. Cugat del Vallès. CSIC, Barcelona, docs. 18 y 136, año 940 y 981: Castaniola.

33 Rius, J. (1945-1947). Cartulari de St. Cugat del Vallès. CSIC, Barcelona, doc. 247, año 990: ... in ipso brugario... Abadal, R. d'. 1926-52. Catalunya Carolingia II. Els diplomes carolingis a Catalunya. IEC, Barcelona., vol.III, doc. 108, año 908: ... in loco qui dicitur Burgali.

34 Rius, J. (1945-1947). Cartulari de St. Cugat del Vallès. CSIC, Barcelona, doc. 24, año 946: Nogaria.

35 Encuesta a J. Cirera de Alzina realizada por J. Solà en el marco del IPEC (Solà, 2003).

36 En el año 1068 Arsenda de Ager deja, en su testamento, la tabla de ajedrez a su esposo Arnau ir de Tost. P. Sanahuja (1961). Historia de la vila de Ager. Barcelona, doc. 25. 
La música y en concreto los instrumentos musicales de las distintas familias, también precisaban de la madera para su fabricación. Las aportaciones de los luthieres actuales nos proporcionan información sobre la práctica artesanal. Los tubos de los instrumentos de viento podían ser de hueso, de caña o de madera, como la del sauco. El tipo de madera utilizado incidía en el timbre del instrumento más duro o más suave según fuera más o menos dura la madera usada, como el boj o el orón respectivamente. Las cajas de resonancia de los instrumentos de cuerda se fabricaban vaciando un tocón de madera más o menos blanda, siendo el tilo una de las preferidas. La tapa se realizaba generalmente con especies resinosas como el pino o el abeto y muy especialmente el ciprés. La madera fibrosa de estas variedades permite extraer lamas delgadas y regulares, óptimas para la función que deben realizar. El puente, el cordal y las clavijas solían realizarse con maderas duras como el boj o el nogal, el peral y el cerezo por su color decorativo. Del mismo modo, los instrumentos de percusión eran, en todo o en parte, de madera. En este caso no todas las maderas eran adecuadas ni ofrecían la misma sonoridad. Los lutieres y constructores de instrumentos de viento y percusión debían ser muy cuidadosos en la selección de las maderas para evitar grietas o nudos que dificultaran la fabricación del instrumento (Calvet, 1999; López-Calo, 1994).

Muy probablemente estos conocimientos sobre los materiales más adecuados para la fabricación de instrumentos deberían ser observados por los luthieres medievales. Como indicación iconográfica, podemos observar las bellas imágenes de la Cantigas a Santa María de Alfonso X o el Pórtico de la Gloria de Santiago. Dentro de los instrumentos de viento no podemos olvidar el pequeño órgano portativo del que disponemos de una bella imagen en un capitel gótico de Santa Maria la Real de Nieva. La arqueología tan solo nos aporta pequeños objetos o fragmentos de instrumentos raramente de madera (Castellet, 2012). Por lo que respecta a textos escritos debemos adentrarnos en la riquísima literatura trovadoresca o en las crónicas donde nos aparecen los nombres de distintos instrumentos y se describen los ambientes donde eran tocados ${ }^{37}$.

Ciertamente la madera empleada en este ámbito no suponía una gran cantidad, pero sí calidad, especialmente por lo que respecta a la construcción de instrumentos musicales.

\section{A MODO DE CONCLUSIÓN: SEMI-AGRICULTURA, ALGO MÁS QUE RECOLEC- CIÓN}

Nos habíamos propuesto identificar actividades productivas vinculadas a la explotación de recursos forestales propias de la Edad Media y aportar datos procedentes

37 Para completar este tema, ver la página de Brassy. Ch. Instruments pour jouer les musiques du Moyen Âge. http://www.instrumentsmedievaux.org. [Consulta: 02/03/2021]. 
de fuentes, ya fueran documentales, arqueológicas o iconográficas. En este sentido consideramos cumplido dicho objetivo.

Este breve repaso nos permite constatar un amplio abanico de recursos, con características diversas que permiten desarrollar múltiples actividades con el objetivo de obtener variados objetos o materiales. Algunos de ellos, como el carbón o la pez, tuvieron aplicaciones de gran trascendencia económica como la producción de hierro o la industria naval, con una repercusión que se extendía mucho más allá de las zonas de producción de estos. En otros casos se trató de producciones que no salieron del ámbito local, pero de gran importancia dentro de las economías domésticas, como la cestería o la producción de pequeños objetos.

En diversas ocasiones hemos recabado datos procedentes de estudios etnográficos y del mundo tradicional para poder aproximarnos a actividades de las que sólo sabemos que se realizaban porque disponemos de determinados objetos que de algún modo deberían producirse. Ciertamente desde el punto de vista científico suelen ser argumentos demasiado débiles como para determinar como se realizaban estas actividades. En todo caso tratamos de sugerir formas de acercamiento a su conocimiento, ya sea con datos directos o indirectos, y poner sobre la mesa su necesaria presencia en el ámbito productivo medieval.

Ante esta avalancha de posibles aplicaciones y valorando la trascendencia de algunas de ellas, nos planteamos hasta qué punto los hombres y mujeres medievales pudieron ejercer una cierta actividad dirigida a potenciar el desarrollo de determinadas variedades vegetales en detrimento de otras. Tareas como la poda, el clareo o la eliminación de especies competidoras, realizadas con la intención de favorecer el crecimiento, expansión y desarrollo de aquellas especies que, por una u otra razón, les resultaban más interesantes y beneficiosas.

Este tipo de tareas, que podemos denominar semi-agrícolas, realizadas en las zonas concurridas habitualmente como en las proximidades de los huertos, fuentes y campos de cultivo, en el entorno de los hábitats o en las zonas de pastos, se realizan aun en la actualidad, tal y como hemos podido constatar en la zona donde hemos realizado nuestras investigaciones arqueológicas los últimos años. Se trata de tareas complementarias altamente productivas porque suponen poco esfuerzo y proporcionan unos beneficios considerables que deberíamos tipificar como algo más que complementarios dentro de las pequeñas economías domésticas medievales.

Si tenemos en cuenta este abanico de actividades productivas y le damos el valor que debieron tener en la Edad Media, la visión que se nos presenta del mundo rural y de sus habitantes cambia radicalmente. Rompemos con la imagen eminentemente agrícola y algo ganadera para construir un mundo complejo, lleno de sabiduría y con una gran capacidad y variedad de competencias practicadas por hombres y mujeres.

El escaso reflejo que estas actividades tienen en la documentación escrita convierte al bosque y sus recursos en los grandes desconocidos y distorsiona la imagen 
de la vida cotidiana en la que la omnipresencia de estos materiales resulta evidente, pues cada día se enciende el fuego, cada día se usa la cuchara o el cuenco, cada día se maneja una herramienta con mango de madera, cada día se coloca en un cesto algún que otro producto, cada día....

\section{REFERENCIAS BIBLIOGRÁFICAS}

ABADAL, R. d'. (1926-1952). Catalunya Carolíngia II. Els diplomes carolingis a Catalunya. Barcelona: Institut d'Estudis Catalans.

ABADAL, R. d'. (1955). Catalunya Carolingia III. Els comtats de Pallars i Ribagorça. Barcelona: Institut d'Estudis Catalans.

Amoric, H. (1990). Practiques et usages de la forêt provençale au Moyen Age. En Actes del 1er i 2 on curs d'Arqueologia d'Andorra (pp. 77-90). Andorra: Patrimoni Artístic Nacional.

BARAUt, C. (1978). Les actes de consagracions d'esglésies del bisbat d'Urgell (s. IXXII). Urgellia, (1), 11-182.

Beltran, J. (2007). Pisa arcaica i vaixella verda al segle XIII. Linici de la producció de pisa decorada en verd i manganès a la ciutat de Barcelona. Quadrens d'Arquelogia i Història de la ciutat, (3), 139-158.

Beltran, O.; Vaccaro, I. (2007). Els comunals al Pallars Sobiràels usos tradicionals de la muntanya en el marc dels espais naturals protegits. Revista d'Etnologia de Catalunya, (33), 142-149.

Benavente, J. A. (2013). Los petroglifos de Alloza (Teruel) y los hornos de aceite de enebro: un enigma resuelto. Historias del Bajo Aragón. http://historiasdelbajoaragon.wordpress.com/2013/04/12/los-petroglifos-de-allozateruel-y-los-hornos-deaceite-de-enebro-un-enigma-resuelto/ [consulta, 02/03/2021]

Bolòs, J. (1982). Anàlisi pol.línica i història medieval. Aportació al coneixement del paisatge pirinenc durant l'edat mitjana. Quaderns d'Estudis Medievals, (10), 635-638.

Bolòs, J. (2004). Els orígens medievals del paisatge català. Larqueologia del paisatge com a font per a conèixer la història de Catalunya. Barcelona: Institut d'Estudis Catalans.

BONHOte, J., Vernet, J. (1988). La mémoire des charbonnières. Essai de reconstitution des milieux forestiers dans una vallée marué par la métallurgie. Revue Forestière Française, (40), 197-210. https://doi.org/10.4267/2042/25884

Bonhote, J.; Davasse, B.; Dubois, C.; IzARd, V.; MÉtAiliÉ, J.P. (2002). Charcoal kilns and environmental history in the Eastern Pyrenees (France). A methodological approach. En S. Thiébault (Ed.), Charcoal Analysis. Methodoligical Approaches, Paleoecological Results and Wood Uses. Procedings of de Second International Meeting of Anthracology (Paris, 2000) (pp. 219-228). Oxford: Archaeoppress. 
BRASSY, Ch. (2014). Instruments pour jouer les musiques du Moyen Âge. http://www. instrumentsmedievaux.org. [Consulta:02/03/2021].

BRINGUÉ, J.M. (2003). Els bens comunals al Pallars Sobirà en el seu context històric. En Béns comunals i la gestió del territori al Pirineu català, els: Actes del Seminari, Què en farem dels comunals? (pp. 21-47). Barcelona: Departament de Medi Ambient. Generalitat de Catalunya.

Calvet, A. (1999). De la pierre au son. Archéologie musicale du tympan de Moissac. Moissac: Accord.

Camiade, M., Fontaine, D. (2005). Appropiation et exploitation du milieu forestier dans la montagne de l'Albera: le cas de la verriere du mas d'en Bonet du Vilar de 1538 à 1666. En Les Ressources Naturelles des Pyrénées du Moyen Âge à l'Ėpoque Moderne (pp. 373-422). Perpignan : CRHISM.

Catafau, A. (coord) (2002). Les Ressources Naturelles des Pyrénées du Moyen Âges à l'Epoque Moderne. Perpignan : CRHISM.

Català, M., Costa, R., Folch, R. (2008). Balanç de catorze anys de l'Inventari del Patrimoni Etnològic de Catalunya. Revista d'Etnologia de Catalunya, (33), 118-141.

Castellet, L. (2012). Paisatge sonor, arqueologia del so. Codis, espais i instruments sonors a la Catalunya rural medieval (ss. X-XIV). Tesi de máster inédita. Barcelona: Universitat de Barcelona.

CAstells, J. (1999). Records de quan feia de pagès. Tremp: Garsineu.

CAVANILLES, J. A. (1797). Observaciones sobre la historia natural, geografía, agricultura, población y frutos del Reyno de Valencia. Madrid: Imprenta Real. https://bivaldi.gva.es/es/consulta/registro.do?id=285

Clemente, J. (Ed.) (2001). El medio natural en la España medieval. Cáceres: Universidad de Extremadura.

Codex... (s. XIV). Codex Granatensis. Repositorio Institucional de la Universidad de Granada http://hdl.handle.net/10481/6525 [Consulta: 02/03/2021]

DAVASSE, B., GAlOP, A. (1989). Le charbon de bois et le pollen: elements pour une approche a de l'evolution historique du paysage forestier des Pyrenées ariégeoise. Acta Biologica Montana, (9), 333-340.

EuBA, I. (2009). La vegetación leñosa y el uso de la madera en tres valles de los Pirineos orientales desde el neolítico hasta época moderna: análisis antracológico, dendrológico y tafonómico. Pyrenae: revista de prehistoria i antiguitat de la Mediterrània Occidental, 40(2), 7-35.

FAbrega, A. (2006). La pega vegetal. Producció i pluriactivitat pagesa. Estudis d'Història Agrària, (19), 69-104.

Ferrer, M. T. (1996). Emprius i béns comunals a l'Edat Mitjana. En J. Busqueta y E. Vicedo (eds.) Béns comunals als Països catalans i a l'Europa contemporània: Sistemes agraris, organització social i poder als Països catalans (pp. 33-65). Lleida: Institut d'Estudis Ilerdencs. 
FERrer, M. T. (2012). El comerç català a la baixa edat mitjana. Catalan Historical Review, (5), 159-193.

García Marsilla, J. V. (2013). Alimentación y salud en la Valencia Medieval. Teorías y pràcticas. Anuario de Estudios Medievales, (43/1), 115-158. https://doi.org/10.3989/aem.2013.43.1.05

Garí, B.; Hernando, J. Riu, M, Sancho, M. Serra, A. (2005). Història Medieval Universal. Textos docents, 25. Barcelona: Universitat de Barcelona.

Gassiot, E. (ed.) (2016). Montañas humanizadas. Arqueología del pastoralismo en el Parque Nacional d'Aigüestortes i Estany de Sant Maurici. Madrid: Organismo Autónomo de Parques Nacionales.

Guilaine, J. (1991). Pour une Archéologie agraire. Paris: Armand Colin. Hernádez Cardona, X. (2001-2004). Història Militar de Catalunya. Vols. I y II. Barcelona: Rafael Dalmau.

Higounet, C. (1966). Les forêts de l'Europe Occidentale de V a XI siècles. En Agricoltura e mondo rurale in Occidente nell'alto Medioevo. XIII Settimana di Studi del Centro sull'Alto Medio Evo (pp. 398-399). Spoleto.

IZARD, V. (2005). La construction des paysages médiévaux. Le rôle fondamen-tal de la métallurgie dans les mutations socia-les et culturelles des VIIe-XIVe. En M. Martzluff (dir.) Roches ornées, roches dressées. Les hommes et leur terres en Pyrénées de l'est (pp. 463-481). Perpignan: Pubications Université de Perpignan.

IZARD, V. (2008). Lapport de l'étude anthracologique à la connaissance du paysage. En O. Passarius, R. Donat y A. Catafau (dirs.) Vilarnau. Un village du Moyen Âge en Roussillon. Canet: Editions Trabucaire. https://doi.org/10.4000/books.pupvd.4263

López-Calo, J. (coord.) (1994). Los instrumentos del Pórtico de la Gloria. Su reconstrucción y la música de su tiempo. A Coruña: Fundación Pedro Barrié de la Maza

Mingote, J.L. (1986). Utillaje agrícola a través de la iconografía mozárabe. En Actas del 1er Congreso de Arqueología Medieval Española, Tomo 1 (pp. 293-312), Huesca: Diputación de Aragón.

Miquel, F. (1945). Liber Feudorum Maior. Cartulario que se conserva en el ACA. Barcelona: CSIC.

Nieto, X., RAUriCH, X. (1998). Culip VI. Excavacions arqueològiques subaquàtiques a Cala Culip. Monografies CASC, núm. 1. Girona: Museu d'Arquelogia de Catalunya. NÖEL, R. (1990). Pour une archéologie de la nature dans le Nord de la Francia. En Lambiente vegetale nell'alto medioevo. Settimane di Studi del Centro Italiano di Studi sull'Alto Medioevo (pp. 763-821). Spoleto.

Ollich, I. (2003). Arqueologia i vida quotidiana a l'època medieval. L'excavació i interpretació d'una casa del segle XIII al jaciment de l'Esquerda. Acta Historica et Archaeologica Mediaevalia, (23/24), 145-165. 
Palet J.M., Ana Ejarque, A., Miras, Y., Riera S.; Euba I., Orengo, H. (2007). Formes d'ocupació d'alta muntanya a la vall de la Vansa (Serra del Cadí-alt Urgell) i a la vall del Madriu-Perafita-Claror(Andorra): estudi diacrònic de paisatges cuturals pirinencs. Tribuna d'Arqueologia, 2006- 2007, 229-253.

PELACHS, A.; SORIANO, J.M. (2003). Las fuentes paleobotánicas y la historia forestal: El ejemplo de los valles de la Coma de Burg y Vallferrera (Pallars Sobirà, Lleida). Cuadernos de la Sociedad Española de Ciencias Forestales, (16), 155-160.

Pelachs, A. (2005). Deu mil anys de geohistòria ambiental al Pirineu central català. Aplicació de tècniques paleogeogràfiques per a lestudi del territori i el paisatge a la Coma de Burg i a la Vallferrera. Tesis doctorals en xarxa. http://www.tdx.cat/handle/10803/4958. [consulta 02/03/2021]

Pinna, M. (1990). Il clima nell'alto Medioevo conoscenze attuali prospettive di ricerca. En L'ambiente vegetale nell'alto Medioevo. Settimane di Studio del Centro Italiano di Studi Sull'alto Medioevo (pp. 431-452) Spoleto.

Puig, I. (1992). El monestir de Santa Maria de Gerri. Barcelona: Institut d'Estudis Catalans.

Raurich, X., Pujol, M., IzQuierdo, P. (1994). Les Sorres X: una embarcació medieval al Delta del Llobregat (Catalunya). En Actas del IV Congreso de Arqueología Medieval Española. Tomo III (pp. 1081-1090). Alicante: Diputación Provincial de Alicante.

Rendu, C., Campmajor, P., Davasse, B., Galop, D. (1994). Habitat, environement et systemes pastoraux en montagne: acquis et perspectives de recherches a partir de l'étude du territoire d'Enveig. En X Col.loqui Internacional d'Arqueologia de Puigcerda (pp. 661-673). Puigcerdà: Institut d'Estudis Ceretans.

Riera, S., Esteban, A. (1994). Vegetation history and human activity during the last 6.000 years on the central Catalan coast. Vegetation History and Archaeobotany, 3(1), 7-23. https://doi.org/10.1007/BF00208885

Riera, S., WANSARD, G., Julià, R. (2004). 2000-year environmental history of a karstic lake in the Mediterranean Pre-Pyrenees: the Estanya lakes (Spain). Catena, (55), 293-324. https://doi.org/10.1016/S0341-8162(03)00107-3

RiUs, J. (1945-1947). Cartulari de St. Cugat del Vallès. Barcelona: CSIC. Roma, J. (2006). El patrimoni natural i cultural. Estudis i recerques. Annals del Centre d'Estudis Comarcals del Ripollès, (20), 11-22.

SANCHO, M. (1999). Homes, fargues, ferro i foc. Arqueologia i documentació per a l'estudi de la producció de ferro en època medieval. Barcelona: Marcombo.

SANCHO, M. (2005). El Montsec entre la serra i la vall: percepció del territori i construcció d'un paisatge a l'Edat Mitjana. En Explotation, Gestion et Appropriation des Ressorces Montagnards du Moyen Âge aux Temps Modernes (pp. 73-87). Perpignan: CRHISM - PUP. 
SANCHO, M. (2009). Mur, la història d'un castell feudal a la llum de la recerca històricoarqueològica. Tremp: Garsineu.

SANCHO, M. (2018). Recursos alimentaris en el monestir d'època visigoda de Santa Cecília de Els Altimiris (Sant Esteve de la Sarga - Pallars Jussà). Primeres aportacions. Revista d'Arqueologia de Ponent, (28), 63-80.

SOLÀ, J. (2003). La muntanya oblidada. Economia tradicional, desenvolupament rural i patrimoni etnologic al Montsec. Barcelona: IPEC, Generalitat de Catalunya.

Tesoros... (2014). Tesoros del Museo Arqueológico, Catálogo, núm. 57371, Arqueta de Abderrahman ben Zeiyan http://ceres.mcu.es/pages/ResultSearch?Museo=MANT \&txtSimpleSearch=Palencia $+\% 28 \mathrm{~m} \% 29 \&$ simpleSearch=0\&hipertextSearch=1\&s earch=advancedSelection\&MuseumsSearch=MANT $\mid \&$ MuseumsRolSearch=36\&li staMuseos=[Museo+Arqueol\%EF\%BF\%BDgico+Nacional+\%28Colecci\%EF\%BF\% BDn+Tesoros+del+MAN\%29] [consulta, 02/03/2021]

Violant i SimorRa, R. (1985). El Pirineo español. Vida, usos, costumbres, creencias y tradiciones de una cultura milenaria que desaparece. Barcelona: Ed. Altafulla.

Wickmham, C. (1990). European Forest in the Early Middle Ages: Landscape and Land Clearance. En L'ambiente vegetale nell'alto Medioevo. Settimane di Studio del Centro Italiano di Studi Sull'alto Medioevo (pp. 479-545). Spoleto. 